\title{
Una Mariposa Transnacional: Memorias desde el Sexilio ${ }^{1}$
}

\author{
Juan A. Ríos Vega ${ }^{2}$
}

\section{Resumen}

A pesar de que Panamá por su posición geográfica ha representado el paso obligado para mucho inmigrantes de todas la latitudes del hemisferio, de los cuales muchos han adoptado este pequeño país centroamericano como su nuevo hogar. En los últimos años frases como "el país donde se vive más feliz" o "una de las economías más prósperas de latinoamérica" llenan a los panameños y panameñas de mucho orgullo patrio; sin embargo, su distribución de la riqueza, la falta de un sistema de salud y educación de calidad hacen que la brecha entre los más pobres y los más ricos sea aún más notoria. Entre las poblaciones que más vulnerabilidad sobresalen están los grupos de lesbianas, gays, bisexuales y transexuales o transgéneros y queers (LGBTIQ+), ya que los mismos tienen una larga historia de invisibilidad. Los colectivos LGBTIQ+ han sido víctimas de opresión tanto verbal como física por las autoridades gubernamentales y grupos religiosos. Por ende la homofobia siempre ha sido aceptada como algo normal e institucionalizado. En este ensayo, el autor utiliza la epistemología de la mariposa transnacional desde su sexilio para documentar de forma cronológica la historia de la homosexualidad en Panamá, desde una perspectiva histórico-social, empezando por la colonización europea, pasando por la presencia estadounidense hasta el presente.

\section{Abstract}

1 . Recibido 11/4/2019 - Aprobado 11/29/2019.

2 . Dr, y profesor de inglés, educación y lingüística comparada en Bradley University, Estados

Unidos. Email: jriosvega @ gmail.com 
Although Panama, due to its geographical position, has represented the obligatory step for many immigrants from all latitudes of the hemisphere, of which many have adopted this small Central American country as their new home. In recent years, phrases such as "the country where you live happier" or "one of the most prosperous economies in Latin America" fill Panamanians with great national pride. However, its distribution of wealth, the lack of a quality health and education system make the gap between the poorest and the richest even more noticeable. Among the most vulnerable populations are lesbians, gays, bisexuals and transgenders, intersexuals, and queers (LGBTIQ +), as they have a long history of invisibility. LGBTIQ + groups have been victims of both verbal and physical oppression by government authorities and religious groups. Therefore homophobia has always been accepted as normal and institutionalized. In this essay, the author uses the epistemology of the transnational butterfly from his sexilio to chronologically document the history of homosexuality in Panama, from a historical-social perspective, starting with European colonization, passing through the American presence to the present.

\section{Introducción}

Hace aproximadamente diez años decidí buscar libros sobre estudios de género y masculinidades en Panamá. Después de visitar varias librerías, me di cuenta de que estos lugares carecían de información sobre el tema. Cuando le pregunté a una empleada de una popular tienda por departamentos por libros sobre el tema, la mujer en cuestión me miró como si fuera un extraterrestre. Todavía interesado en el tema, al día siguiente decidí visitar otra librería. Esta vez recorrí Vía Argentina hasta encontrar una librería bastante conocida por escritores, profesores y estudiantes universitarios, de la cual mi sobrino me había hablado muy bien; pensé que allí podría encontrar obras de algunos escritores locales o profesores de la universidad que hubiesen publicado algo sobre el tema de mi interés. Cuando entré en la librería, había dos hombres de mediana edad charlando sobre cosas que podrían hacer para atraer más clientes a la librería. De inmediato, decidí acercarme a los dos caballeros (uno, con acento extranjero) y hacerles saber de mi búsqueda de temas de género y masculinidades en Panamá desde el punto de vista académico. Me dio la impresión de que mi presencia y el carácter de la búsqueda les intimidó un tanto. Nuestra conversación resultó ser muy interesante, ya que el dueño de la librería me dio algunos nombres de escritores, revistas y sitios web donde probablemente podría encontrar alguna información sobre mis temas. Sin 
embargo, lo más interesante de la charla con estos dos señores fue descubrir cómo ellos entienden la orientación sexual en Panamá, traté de explicarles que la palabra masculinidad no se refería a un concepto sencillo y homogéneo, además de que algunos hombres heterosexuales tienen sexo con otros hombres y a pesar de ello continúan afirmando que son hombres heterosexuales. En su lugar, la sociedad panameña entiende ser gay como hombres que se ven y actúan muy afeminados, que son penetrados, y se sienten y visten como las mujeres. Como era de esperar, estos dos caballeros mencionaron algunos ejemplos de lo que es ser gay en Panamá, mientras sostienen que los gays suelen ser considerados aquellos que se dedican a ganarse el sustento como estilistas de cabello, diseñadores de trajes de carnaval y atuendos para concursos de belleza, o bailarines de ballet. Más tarde, compartí con ellos que en Panamá hay un criterio doble cuando las personas se refieren a la orientación sexual; por lo general la asocian con el VIH/sida. Por otro lado, cuando los gays manifiestan su inclinación sexual abiertamente, las corporaciones y los canales de televisión locales los utilizan como una atracción en sus programas para burlarse de ellos y / o para aumentar sus audiencias. Durante este intercambio, supe que el otro caballero era profesor de derecho en una universidad local. Él compartió conmigo que aunque su hijo es un bailarín de ballet, él sabía que su hijo no era gay. Después de mi visita a esta reconocida librería, me sentí frustrado en mi búsqueda y decidí regresar a Vía España y tomar el camino a casa.

A través de la literatura panameña varios han sido los escritores que han incluido el tema de la homosexualidad y el lesbianismo en sus personajes. No fue hasta principios de los 70's cuando autores como como Agustín del Rosario, poeta, ensayista y teatrista, quien ganó el Premio Nacional de Literatura Ricardo Miró en la categoría de poesía con su libro "De Parte Interesada". Desafortunadamente, por la profundidad del tema homoerótico y la época, su obra causó mucha controversia entre algunos jurados del concurso y la misma tuvo que ser publicada en México.

En 1996 Javier Stanziola gana el Premio Ricardo Miró con su obra de teatro De Mangos y Albaricoques, en la que Fabricio, un joven homosexual panameño vive en un exilio sexual en Miami desde donde relata cómo la opresión y el rechazo por su orientación sexual marcaron su infancia y adolescencia en Panamá. Para Fabricio, el vivir su exilio es sinónimo de libertad en comparación a insilio que viven sus pasieros (amigos) en Panamá. Sin 
embargo, en sus viajes a Panamá, sus pasieros les recuerdan como es vivir en el insilio y como resistir los espacios de opresión. Stanziola (2013) comenta que en su obra el pasiero "se libera, aunque sea temporalmente, de esa opresión sistemática" (p. 18). En 2009, Stanziola gana el premio Ricardo Miró en categoría teatro con la obra Hablemos de lo que no hemos vivido. En esta obra, se desarrolla el tema de la identidad personal y el reinventarse desde el insilio. Stanziola una vez más gana el Premio Ricardo Miró en novela con Hombres Enlodados en 2013. Dicha novela transcurre durante la dictadura de Manuel Antonio Noriega y es contada por Jota Jota, un joven adicto a las telenovelas y concursos de belleza. Jota Jota no cumple los estándares sociales para considerarse totalmente masculino, llevándolo así a ser víctima de la opresión y acoso.

\section{La Conciencia de la Mariposa Transnacional desde el Sexilio}

Stavans (1996) sostiene que los homosexuales representan el otro lado de la sexualidad hispana, una sombra que se rehúsa a reconocer - que "ellos" en realidad es "nosotros". Ellos son el alabado, adelito, afeminado, ahembrado, amaricado, amujerado, barbilindo, carininfo, cazolero, cocinilla, enerve, gay, homosexual, invertido, lindo, maría, marica, mariposa, ninfo, pisaverde, puto, repipí, sodomita, volteado, zape (p.155).

A partir de las epistemologías de los queers de color y la conciencia mariposa de Daniel Enriquez Pérez (2014), expando mi conciencia de la mariposa transnacional. Como un hombre latinoamericano que se identifica como un queer de color en Estados Unidos, pero al viajar constantemente a mi patria, Panamá, mi cambio de identidad me empuja a adoptar una identidad gay. Basado en estos cambios geográficos de transnacional, comparto mis experiencias personales como inmigrante y hombre haciendo de lo político (homosexualidad) algo personal (maricón, cueco, loca, pato). Es importante entender que para desarrollar mi propia conciencia de mariposa transnacional necesito conocer mi propia historia y abrazar todos los elementos de mis identidades mutantes. Entiendo que no puedo sentir vergüenza de quién soy o de lo que hago naturalmente. Uso el término mariposa como un símbolo de viajero, de cruce de fronteras, lente crítico, y de defensa. Pérez (2014) afirma que muchos 
artistas y escritores chicanos y latinos han usado imágenes de mariposas para desarrollar una consciencia mariposa como teoría descolonizadora y como "símbolo de transformación, vida, muerte, resistencia, migración y alma" (p. 99). Como mariposa transnacional, sigo cruzando fronteras territoriales y sociales que a veces me dejan exhausto y desesperado. Este cruce de fronteras que me hace pensar acerca de mi propio ser en términos de una persona que se define como queer de color en los Estados Unidos y gay en Panamá. Este cambio de identidad transnacional es el que siempre me recuerda que vivo lo que Anzaldúa (2007) definía como "fronteras, un lugar vago e indeterminado creado por el residuo emocional de un límite no natural" (p.25), haciéndome comprender que pertenezco a "los atravesados". Esta conciencia transnacional me permite desarrollar mi propia conciencia de la mariposa. Aprendo a ser queer de color en un espacio, pero también adquiero conciencia de mi carne y mi alma como gay en otro espacio.

Como mariposa transnacional, me siento oprimido y discriminado por ser un latino en los Estados Unidos, el cual representa el estereotipo de un inmigrante indocumentado por mi aspecto mestizo, mientras que en Panamá, vivo bajo los conceptos de homofobia, sexismo, racismo, clasismo y otras capas de discriminación que cultiva la sociedad como algo normal. Entiendo que tengo que enfrentar la homofobia y una sociedad de doble moral en Panamá y un espacio racista y xenófobo en los Estados Unidos. Como la mestiza de Anzaldúa (2007), tengo una "lucha de fronteras, una guerra interior" (p. 25). Mientras vivo en dos culturas y países diferentes, recibo mensajes diferentes de la gente. En los Estados Unidos, puedo ser oprimido por hablar inglés con acento latino, mientras que en Panamá, me siento oprimido debido a mis manerismos o por ser etiquetado maricón, cueco, o loca. Una sociedad que juzga mi soltería y mi edad como indicativo de que no soy totalmente hombre porque nunca me casé y no tengo hijos. Es ese constante recordatorio de que no soy "completo". ¿Sigues soltero? ¿Cuándo se va a casar?, o escuchar amigos y familiares usar insultos homofóbicos contra hombres cuyo perfil se ajusta a una conducta gay o, juicios similares a "tú eres gay pero no actúas como aquellos que se comportan como las locas”.

Como la mestiza de Anzaldúa (2007), mi conciencia de mariposa transnacional me hace más reflexivo sobre mí mismo y mi cambiante identidad. Considero este cambio de identidad como una constante transformación hacia consciencia mariposa. Es durante esta 
transformación cuando abro mis alas y encuentro la liberación; son mis escritos, mis testimonios, los que me permiten experimentar mi fortaleza. Pérez (2014) agrega:

Tener conciencia mariposa es reconocer "nuestra belleza y fortaleza interior y exterior; se trata de ser tú mismo en tu verdadera naturaleza, en tus propias palabras, en toda tu mariposada, todo el esplendor de tu belleza, tu fortaleza, tu propia expresión de género y sexualidad. Se trata de conocer tu historia y a ti mismo plenamente, y abarcar todos los aspectos de tu identidad. Se trata de mantener un equilibrio físico y mental para que puedas volar en toda su gloria (p. 102).

Como resultado de mis investigaciones y reflexiones como hombre queer/gay/marica decidí escribo acerca de la homosexualidad en Panamá, utilizando la conciencia de la mariposa transnacional para documentar la realidad de las poblaciones LGBTIQ+ desde mi sexilio. Autores y autoras caribeños como Adela Vásquez, Manuel Guzmán y Lawrence La FountainStokes se han referido al sexilio como la migración forzada como mecanismo de resistencia entre las minorías sexuales, especialmente las comunidades LGBTIQ+. Este sexilio permite a las minorías sexuales a buscar espacios de aceptación que le permitan existir y resistir la homofobia y la falta de leyes que protejan específicamente a las poblaciones LGBTIQ+. Ha sido mi propio sexilio el que me ha permitido publicar La conciencia de la mariposa transnacional: para entender la homosexualidad en Panamá (Convivencia, 2017), An unhealed wound: Growing up gay in Panama (Bilingual Review/La Revista Bilingüe (2017) y también presentar mis escritos y testimonios en conferencias internacionales. A finales del 2018, publiqué el libro Historias desde el Sexilio (Ríos Vega, 2018). En su reseña del libro, Luis Pulido Ritter (2018) opina lo siguiente:

El libro ha sido producto de mis investigaciones a lo largo de estos últimos años. Los temas son relevantes y actuales, pero enfocados desde un punto de vista de justicia social. El libro hace eco de los testimonios dentro de las comunidades LGBTIQ+, pero que muchas veces son satanizadas por una falta de conocimiento del tema, por temor a hablar debido al rechazo familiar y por la doble moral que predomina en el país debido a creencias religiosas. Hablar de estos temas a través de mi libro es una 
forma de mostrar a una población algo que es desconocido, pero también es una forma de encontrar comunidad dentro de las personas LGBTIQ+ en Panamá".

Durante mi reciente visita a Panamá con motivos de la presentación de mi libro, pude aprender de que existe una nueva corriente de escritores y escritoras interesados en publicar sus escritos con temas homoeróticos. Pude conocer a escritores emergentes, tanto nacionales como extranjeros, interesados en escribir y publicar literatura homoerótica en Panamá. También pude conversar con escritores ya consagrados que aún tienen el temor a ser rechazados o a no conservar sus trabajos si publican sus escritos homoeróticos. Otro obstáculo que predomina en Panamá es la falta de fondos para publicaciones ya que el publicar es muy costoso. A continuación hago un recuento cronológico de la homosexualidad en Panamá para entender que tanto hemos logrado hasta el presente siglo. Stavans (1996) comenta que en las sociedades latinoamericanas son muy pocos los que se atreven a tocar el tema de la homosexualidad, lo que conlleva a que muchos gays y lesbianas siguen siendo objeto de mofa y burla, forzandolos a vivir en las franjas marginales de la sociedad. Ser gay es ser un monstruo o es estar mentalmente enfermo...y es la homosexualidad, un tema que pocos están dispuestos a analizar en público, el contrapunto que define nuestra identidad colectiva.

\section{Época Colonial}

Debido a que no estábamos destinados a sobrevivir, la mayoría de los jotas/os hemos forjado una madurez espiritual única, ubicada al margen de las instituciones tradicionales. Esta madurez nos ha permitido concentrar nuestras energías en combatir el colonialismo y la opresión y reunir un archivo de espacios y prácticas curativas que satisfacen nuestras necesidades espirituales (Calvo-Quiros, 2014, p.192).

Antes de 1492, no existía ningún mapa que representara el continente americano pues este no había sido descubierto aún para los habitantes de Europa y Asia. Los grupos humanos que habitaban estos territorios, los designaban con diferentes nombres: Tawantinsuyu, en los Andes; Anáhuac en lo que hoy es el valle de México, y Abya Yala lo nombraron los indígenas Gunas que habitaban territorios de lo que hoy es Panamá y Colombia. Mignolo (2005) afirma que: "Los pueblos de Europa, Asia, y África no tenían idea de la existencia de este bloque de tierra masivo que más tarde llamarían Indias Occidentales y luego América" 
(p. 2). A lo largo de la historia, los estudios tradicionales muestran a los grupos indígenas y su forma de vida a través de un enfoque que los presenta como seres primitivos, inferiores, y poco inteligentes. Muchos académicos poscoloniales (Bañales, 2014; Coloma, 2013; Cruz, 2012; González, 1996, 2006; Hames-García, 2014; Hames-García y Martínez, 2011; Ocampo, 2012; Pérez, 2014; Rodríguez, 2003; Tuhiwai Smith, 2002; Tijerina Revilla y Santillana, 2014; Urrieta, 2003) interpretan a los indígenas y a otros grupos marginados desde una perspectiva no tradicional. Tuhiwai Smith (2002) afirma que "bajo el colonialismo, los pueblos indígenas han luchado contra una visión occidental de la historia y, sin embargo, han sido cómplices con ese punto de vista. A menudo, hemos permitido que cuenten nuestras "historias" y luego, nos convertimos en espectadores del proceso"(p. 33). Este pensamiento ha llevado a diferentes grupos y catedráticos que representan o abogan por los más vulnerables a elevar sus voces y contar las realidades de los que siempre han estado invisibles, desafiando así aquellos que utilizaron su poder, posición social, e interpretación para documentar en forma errónea las vivencias de otros.

A pesar de que en América Central y el Caribe se han realizado muy pocos estudios sobre las prácticas sexuales durante el periodo precolombino, algunos han revelado una definición diferente de la sexualidad de aquella que se le da hoy día. Las crónicas escritas en los siglos XV, XVI, y XVII se refieren a diferentes formas de homosexualidad como prácticas comunes a las que los europeos llamaron sodomía. (Diversidad sexual en AbyaYala). Sigal (2003) citó:

Cuando los españoles y los portugueses escribieron sobre la Conquista de América Latina, describían a los pueblos indígenas en términos denigrantes. Probablemente las imágenes más extraordinarias a los ojos de los europeos presentadas en estas crónicas de la conquista eran el sacrificio humano, el canibalismo y la sodomía (p. 1).

No hay duda de que los europeos utilizaron sus creencias homofóbicas y racistas para convencer a los indígenas de que sufrían enfermedades e inundaciones como castigo de Dios por tener relaciones sexuales entre personas del mismo género. Trexler (1995) sostiene que la sodomía u homosexualidad masculina les facilitó a los europeos la conquista, proclamando ante la gente indígena que la sodomía era su perdición. Por esta razón, “el vengativo dios cristiano había decidido enviar a los íberos para tomar a América ya que ellos se habían entregado a prácticas homosexuales" (p. 84). El ejemplo más atroz de la conquista europea, 
especialmente lo que ellos llamaron un castigo por actos de sodomía y, el primer relato de la homosexualidad en el continente americano, ocurrió durante el tránsito de Balboa a través del istmo de Panamá.

Aparte de una mera insinuación de Álvarez Chanca sobre un "berdache" militar en su carta de 1494, el doméstico "berdache" americano aparece claramente, por primera vez, en los relatos del descubrimiento del Pacífico por Balboa en 1513. En la tercera década de la obra del italiano Pedro Mártir de Anglería, De orbe novo, publicado en 1516, cuenta cómo, en su viaje por Panamá, Balboa encontró a un hermano del cacique Quaracuá y algunos de sus hombres vestidos de mujeres y practicando la sodomía; el conquistador aplicó una especie de Ley Scantinia de Nefanda Venere, arrojando inmediatamente a los perros a unos cuarenta de estos travestis, aunque no a sus compañeros activos. Este es el primer registro de castigo español de la sodomía en el continente americano. Según Pedro Mártir, todo sucedió mientras los nativos aplaudían, "porque el contagio estaba confinado a los cortesanos y no se había extendido todavía al pueblo" (Trexler, 1995, p. 82).

Los estudios de Trexler antes y durante el periodo español y portugués nos permiten comprender el ejercicio y aplicación de los roles de los géneros en un contexto histórico. Sin embargo, su definición occidentalizada, al referirse a los hombres de género no tradicionales como "berdache," perpetúa la idea de una conducta de género incorrecto o negativo, que fue aceptado completamente por los indígenas antes de la colonización. Sin embargo, los más recientes escritos indican que varios Indios Americanos gays, lesbianas, transgéneros, y otros de "two-spirit" (doble espíritu) consideran el término "berdache" como peyorativo y hasta un insulto (Jacobs, Thomas, \& Lang, 1997; Driskill, Finley, Gilley, \& Morgenesen, 2011). Es claro que Balboa y su gente utilizaron el cristianismo para convencer a aquellos pueblos que estaban viviendo en pecado y que su dios les había enviado a salvarles; sin embargo, ellos a su vez crearon una actitud hacia el comportamiento del género y convencieron a los indígenas de que la sodomía u homosexualidad era contagiosa. Balboa y los demás españoles dejaron sentado que no tolerarían ningún tipo de acto sexual no tradicional (hombre y mujer), incluidos los de hombres que se vestían como mujeres o que llevaran a cabo actividades propias de mujeres (Sigal, 2003). Este ejemplo deja plasmado como a través de la 
colonización, los europeos implantaron el binario hombre/mujer, eliminando y castigando todo tipo de manifestación de género que estuviera fuera de lo que ellos consideraban normal.

Sorprendentemente, los hombres afeminados o vestidos de mujeres resultan una visión negativa y pecadora la cual predomina en las sociedades latinoamericanas, a pesar del paso de los siglos. En Panamá, por ejemplo, la iglesia católica y el gobierno han influido en la sociedad común, en la que promueven la idea de que la homosexualidad constituye una amenaza para la humanidad. Esta perspectiva ha obligado a que las muchas personas que no se acogen al binario hombre/mujer abandonen a sus familias para ocultar su orientación sexual y llevar una doble vida (en algunos casos los hombres hasta se casan con una mujer para complacer a sus familias y a la sociedad, mientras mantienen relaciones sexuales con otros hombres). Otros deciden internalizar patrones de conducta implantados por la sociedad asociados a los gays y lesbianas.

Javier Stanziola (2003) expone que en Panamá como en la mayoría de los países de América Latina, las parejas del mismo sexo no se pueden casar ni adoptar niños. Por lo tanto, los gays no tienen otra alternativa que la de abandonar su país para encontrar la libre determinación sobre ambos temas. Stanziola dice: "La única alternativa es emigrar y reinventarnos en aquellos lugares donde nuestra identidad panameña no es estereotipada o sea incluida en un grupo único y estático, ya sea en Europa o en un área rural en los Estados Unidos” (p. 16). Desafortunadamente, cuando en una familia hay un miembro de la misma que es gay, los padres o parientes evitan hablar de esa persona y actúan como si no existiera, lo cual muestra que continúan considerando esta conducta sexual como pecadora y hasta vergonzosa. Otros creen que los jóvenes que eventualmente participan de esta conducta sexual diferente a la de su género, cambian al alcanzar la madurez, por razones religiosas o de familia.

\section{Presencia Militar Estadounidense}

A través de nuestra historia, pero sobre todo durante la presencia militar estadounidense en el istmo, muy poco se ha tocado el tema de la homosexualidad. Joaquín Beleño (1991) en su obra literaria Gamboa Road Gang/Los Forzados de Gamboa, explica cómo eran definidos y tratados los homosexuales dentro de las cárceles en la base militar en Gamboa. 
Los homosexuales, personajes pintorescos, le dan colorido a cualquier institución. Son despreciados la mayoría de las veces por los hombres; pero esto no es óbice para que sirvan de motivo de distracción a toda la tropa de reclusos. Alrededor de sus gestos y contoneos se teje todo un mundo festivo de intrigas picarescas. El homosexual tiene la doble ventaja de aproximarse como hombre y tener la mentalidad femenina. La naturaleza lo ha traicionado biológicamente. Sin embargo, es alegre y se deja entusiasmar con cualquier lisonja pasajera (p. 116).

A pesar de que Beleño narra la existencia de presos homosexuales tanto panameños como estadounidenses dentro de las antiguas bases militares, esto no establece el concepto de un homosexual amanerado o con gestos femeninos, sino la idea de un hombre con ansias de ser y sentirse mujer. La presencia de bases militares estadounidenses en territorio panameño (1903-1999), muestran también la existencia de la mencionada subcultura gay en Panamá como parte del capitalismo. Era muy común presenciar como mujeres y, también hombres, esperaban en las entradas de algunas bases militares para que algún soldado les permitiera entrar a la base. Estas áreas se convirtieron en los espacios perfectos para la prostitución y los encuentros entre personas del mismo sexo. Donoghue (2014) sostiene:

Los esfuerzos de Estados Unidos por imponer control sobre la actividad sexual en las fronteras "proporcionaron un sitio clave para la producción y reproducción de categorías, identidades y normas sexuales" entre las desiguales relaciones atípicas que pululaban a todo lo largo de la frontera imperialista. Por ejemplo, la policía de la zona del canal y los policías militares (MP) con frecuencia arrestaban a "los transgresores sexuales" a lo largo de las fronteras del enclave, les asignaban categorías, les clasificaban y les adscribían conductas e identidades las cuales muchas veces eran falsas, erróneas o hechas a la medida de la misión que ejercía el control estadounidense en la zona fronteriza. Así, las amantes panameñas eran prostitutas, los afeminados eran colombianos homosexuales y los panameños que se disfrazaban durante el carnaval, eran travestis (p.131).

Era del dominio público y se oía con frecuencia a la gente hablar sobre los soldados de los Estados Unidos que tenían relaciones sexuales con hombres vestidos de mujer y con prostitutas quienes acostumbraban esperarlos a las salidas de las bases militares de la Zona del Canal durante la noche. La salida de la Avenida 4 de julio (July 4th) era una sitio popular donde muchos gays y prostitutas esperaban a sus clientes para sus escarceos 
sexuales. Donahue (2014) cita que "en ocasiones, algunos soldados estadounidenses informaron que habían sido violados en territorio panameño por hombres panameños" ( $p$. 158). Sin embargo, las autoridades dudaron siempre de estas excusas de los soldados cuando presentaban sangrados o enfermedades venéreas anales ya que, incidentes previos demostraban que también este tipo de prácticas sexuales entre personas del mismo sexo se daban dentro de las bases militares de los Estados Unidos. Hoy dia esta popular avenida conocida como La Avenida de los Mártires, guarda en silencio los tantos encuentros carnales entre soldados norteamericanos y gays y/o travestis locales.

\section{Militarismo Criollo}

Durante el periodo en el que Noriega ostentaba el poder, el lado bisexual de su personalidad surgió en forma más evidente pero encubierta por su imagen de macho cuidadosamente elaborada. El oficial machista, que dominaba el judo y el paracaidismo, se perfumaba profusamente en sus horas libres, se ponía monos y zapatillas amarillos, atravesaba el mundo con su novio piloto, con quien se rumoraba llevaba un tórrida relación y se rodeaba de gays declarados que fungían de embajadores y consejeros (Kempe, 1990, p.83).

Otro periodo oscuro de la historia moderna panameña es la de los regímenes militares (19681989), quienes se ensañaron contra los que se oponían a la opresión y la persecución. Políticos y civiles que se resistían contra Noriega, incluso los homosexuales, fueron víctimas de persecución, opresión, encarcelamiento, abusos verbales y físicos, y hasta de violación sexual. Koster y Sánchez (1990) narran como el Dr. Ricardo Arias Calderón, destacado filósofo y político panameño, fue arrestado el 9 de junio de 1987 después de haber participado en una protesta contra la dictadura de Noriega.

Más tarde, en el patio del G-2, Ricardo y otros que estaban con él fueron obligados a acostarse boca abajo en el piso y se les amenazaba con violarlos, mientras se les ponían condones frente

al rostro y se les amenazaba con colocarlos en celdas donde serían violados por otros prisioneros, muchos de los cuales padecían de sida (Koster \& Sánchez, 1990, p. 334).

Todavía recuerdo cuando era un adolescente, solía escuchar comentarios sobre políticos que se oponían al régimen de Noriega y eran violados en la cárcel. Otros, en broma, advertían a los ciudadanos que esto es lo que les podía suceder si quebrantaban las leyes. Un ejemplo 
más de hombres teniendo sexo con otros en forma abusiva, se daba en la infame cárcel de Panamá llamada "La Preventiva". Este era un destartalado, reducido y caluroso recinto donde se llevaba a la mayoría de los hombres después de ser arrestados. En este lugar, los gays eran violados por otros prisioneros, generalmente criminales y por los mismos oficiales de policía.

Algunas veces después de la medianoche, el sargento vistiendo pantalones jeans traía cigarrillos de marihuana para los criminales que habían servido de acosadores. Esto les calmaba, pero entonces lanzaban a una mujer dentro de la celda. Solo lucía como mujer pero, en realidad, era un hombre travesti en tacones altos, ajustados pantalones a la pantorrilla y una blusa rosada. Y, claramente era un visitante frecuente de la Modelo pues los criminales le llamaban por el apodo de "Carolina". Con gran entusiasmo, (siguiendo lo que parecía un orden jerárquico establecido) comenzaron a hacer uso sexual de él. Con su consentimiento primero, o al menos su resignación, y luego, a pesar de sus ruegos y protestas, sus sollozos y sus lágrimas - se llevaron a cabo veinte o más actos de relaciones sexuales orales y anales, mientras eran aupados por los que ya habían acoplado o estaban esperando y le propinaban puñetazos, le torcían las orejas y vociferaban para alentar a "Carolina” (Koster \& Sánchez, 1990, p. 346).

Esta constante actitud abusiva se organizaba a veces ante los políticos arrestados como una amenaza de lo que les podía suceder a ellos más tarde. El hecho de que los homosexuales fueran objeto de abuso sexual y violación mientras estaban en prisión, se consideraba un castigo justo por ser gays declarados. Un buen ejemplo de cómo se señalaba a los hombres gays en Panamá es el tema central de la obra de teatro "La Madrid", creada por Salas Fonseca (2005):

Ezequiel: Por la hijueputa salazón que cargo, me pillaron escribiendo con pintura de spray,

“Noriega Maricón”. . . Coño, me puse del mismo color de la pintura. . . ¡blanco!

Anel: ¿Y entonces?

Ezequiel: Lo bueno fue que el tongo que me agarro era como medio gay. Tú sabes que lo 
primero es dar de toletazos y luego preguntan. Este me trato como una princesa. Me mandaron para el cuartel de Tinajitas y me encerraron con unos chombones de alta peligrosidad, dizque para que mi noche fuera tortuosa.

"La Madrid" era un tugurio marginal cuya clientela estaba compuesta por individuos de diferentes extractos sociales y experiencias. Es un sórdido, estrecho y maloliente bar, situado en el Casco Viejo de Panamá donde homosexuales, lesbianas, intelectuales, prostitutas y hasta drogadictos compartían sus historias; donde a nadie se le preguntaba o exigia una identidad. La Madrid era un espacio libre de riesgos para aquellos que buscaban un espacio neutral para confrontar las normas sociales y creencias religiosas. La historia de Ezequiel no es ajena a muchos gays que frecuentaban La Madrid para reunirse con amigos nuevos y antiguos.

\section{La Homosexualidad en el Panamá de Hoy}

Debido a que las conversaciones sobre orientación sexual y las relaciones entre personas del mismo sexo han sido siempre tabú, esto ha movido a los grupos LGBTIQ+ a formar su propia subcultura. Ser gay o lesbiana declarados es todavía tema de castigo y la sociedad lo considera un acto inmoral. Por ejemplo, los gays y las lesbianas no son protegidos por ciertos derechos humanos: no tienen acceso a muchos campos laborales decentes y son muchas veces marginados por sus familias y por la sociedad en general. El Departamento Nacional de Policía, no admite lesbianas ni gays. Por el contrario, son considerados peligrosos para los demás, agresivos, poco inteligentes, adictos al alcohol, y violadores de niños. Por otro lado, hay informes de oficiales de policía que cometen abuso verbal y sexual contra los transexuales y los transgéneros. Los gays son víctimas de abuso sexual, de trato violento y abusivo y a algunos se les pide dinero en forma ilegal por parte de oficiales de la policía. (R. Beteta Bond, comunicación personal, 2 de Julio de 2016). 
Los medios de comunicación locales también discriminan a los gays y lesbianas en términos despectivos y discriminatorios, perpetuando una sociedad de doble moral. Por ejemplo, el individuo homosexual es rechazado por la sociedad y la religión cuando demuestra abiertamente su naturaleza, pero por otro lado, al mismo individuo se le acepta si al definirse se amolda al patrón que la mayoría considera que debe ser su sitio en la sociedad cuando se declara gay o lesbiana: un hombre que es afeminado, puede ser sólo estilista, diseñador de moda o alguien que ama los concursos de belleza y las reinas de carnaval. Esta sociedad de doble moral empuja a muchos que se reconocen como homosexuales y lesbianas a mantener su orientación sexual como algo privado. Por desgracia, este tipo de opresión hacia el grupo LGBTIQ+ y la internalización de esta homofobia por la mayoría de gays y lesbianas no declaradas, se suele interpretar como normal.

Marlin Estela González, en su artículo “Derechos sexuales en Panamá y su invisibilización en el Estado" (2018), nos comparte que en Panamá aún persiste la discriminación estereotipada hacia la población LGBTIQ+. González explica como el artículo 133, numerales 11 y 12, del Decreto Ejecutivo 204, del Reglamento Interno de la Policía Nacional, se considera como falta gravísima la homosexualidad y el lesbianismo, y ambos son castigados con arresto de hasta sesenta días o la destitución del cargo (90). González manifiesta que Panamá tiene leyes que permiten que exista la violencia y la exclusión hacia las comunidades LGBTIQ+, prohibiendoles su desarrollo para que estas personas puedan alcanzar una justicia social. Siendo ésta la Primera Asesora Jurídica del Comité de Derechos Humanos en Panamá, manifiesta que durante su cargo hubo denuncias hasta de tortura contra 
personas trans, detenidas por la policía, colocadas en condiciones infrahumanas y privadas de alimentos (González, 2018).

Por su parte, Ricardo Mejía Miller, quien es fundador de Independientes Pro-Derechos Humanos (IPDH) en Panamá, nos comenta que por falta de una ley que garantice la protección de los derechos humanos de las personas LGBTIQ+, éstas solo se limitan a denunciar a instituciones gubernamentales, medios de comunicación y redes sociales, con resultados poco prometedores o cambios en beneficios de la población en mención.

Personalmente, considero que aunque se han generado espacios desde los organismos internacionales principalmente, los resultados de estas reuniones no han trascendido a las normas nacionales y regionales. El proceso se mantiene en la misma fase y no se ha dado un salto adicional que promueva la incidencia política en la toma de decisiones a todos los niveles (R. Mejia Miller, entrevista personal, 19 de diciembre de 2018).

Su intervención demuestra que a pesar de que el Estado panameño asegura igualdad de derechos para todos sus ciudadanos, aún persiste una discriminación institucionalizada y a su vez perpetuada por estamentos del Estado, donde en muchas ocasiones personas con poder social, como la policía nacional, hace uso de sus creencias religiosas personales para discriminar y oprimir a la población LGBTIQ+. A pesar de que la Ley Ejecutiva N$^{\mathbf{0}} 332$ de 29 de julio de 2008 eliminó el artículo 12 de la Ley 149 de 20 de mayo de 1949, que penalizaba la sodomía (palabra usada para nombrar a la homosexualidad antes de 1973), las cosas no parecen mejorar en la sociedad panameña en cuanto a su visión de un grupo LGBTIQ+ más inclusivo. Todavía existen algunas normas y regulaciones institucionalizadas basadas en creencias religiosas, una sociedad de doble moral y agendas políticas que obstaculizan la creación de una ley estatal que proteja y garantice derechos legales a los grupos LGBTIQ+.

El poco avance contra el VIH/sida no está acorde con lo planteado de erradicar la enfermedad en 2030. Para el año 2010 existían 0.8\% del total de personas entre 15 y 49 años infectadas con VIH, y para el 2017 la cifra subió al 1\%. Según datos compartidos por el Ministerio de Salud (Minsa), Panamá reportó su primer caso de sida en 1984 y hasta octubre de 2018, se han documentado 16 mil 723 casos y 11 mil 336 muertes. Lo más alarmante de estas 
estadísticas es que según las autoridades los casos de VIH/sida son más comunes en jóvenes entre 15 y 24 años, e indígenas (Samaniego, 2018). La falta de insumos por parte del Estado, la pobreza y una educación sexual tanto en las escuelas públicas, hace que esta parte de la población sea más vulnerable a las enfermedades de transmisión sexual como el VIH/sida.

A pesar de que en Panamá existe el Artículo 70 del la Ley 100 de 30 de diciembre de 1974 y Artículo 75 del Decreto 121 del 6 de noviembre de 1995 que permite cambiar el nombre de la persona en su cédula debido al cambio de sexo, no existe una ley de identidad de género, lo que provoca una discriminación institucionalizada hacia la población transgénero. Panamá permite cambiarse el nombre si la persona demuestra tres pruebas de que ha usado ese nombre en los últimos cinco años. Sin embargo activistas trans opinan que estos trámites burocráticos violan los derechos humanos de las personas trans ya que los mismos requieren una serie de exámenes médicos, los cuales pueden durar mucho tiempo y a la vez pueden ser bastante costosos. Al no poseer un documento legal como lo es la cédula de identidad personal que corresponda a su identidad de género expone a la población trans a ser víctimas de burla y acoso, especialmente en la instituciones públicas. Muchas mujeres trans son llamadas por su nombres masculinos en los centros de salud o en varias ocasiones en algunos bancos les piden que regresen sin maquillaje y peluca cuando la mujer trans no concuerda con la de la foto en el documento legal. Panamá tampoco cuenta con una ley que penalice la discriminación por orientación sexual. Esto deja al colectivo en la desprotección absoluta. Los arrestos por crímenes de odio quedan impune ya que no existen cifras oficiales sobre arrestos físicos porque los fiscales no clasifican los crímenes basados en identidad de género. A su vez, las víctimas no acusan por miedo o desconfianza en las autoridades.

Dos grandes acontecimientos han sacudido a la sociedad panameña al momento de escribir este ensayo. Primero, el padre David Cosca, popular párroco de la iglesia católica en Panamá, 
aparece involucrado en el caso del asesinato de Eduardo Calderón en El Hotel El Panamá. Según declaraciones de personas allegadas a Hidadi Saavedra, quien es amigo del padre Cosca y a quien se le acusa de haber asesinado a Eduardo Calderón, sostenía una relación más allá de una amistad con Cosca. Lo curioso de este hecho es que la habitación del hotel fue arrendada por Cosca, a quien se le acusa de encubrir la verdad de los hechos. Hidadi Saavedra fue encontrado culpable de este crimen y hasta esta fecha el padre Cosca está a la espera de su juicio. El segundo hecho que sacudió a la iglesia católica fue la grabación por parte de un inmigrante venezolano quien realizaba trabajos sexuales a algunos párrocos en la capital. Esto provocó la publicación de más líderes religiosos involucrados en actos de homosexualidad. Según la prensa local, los curas Rogelio Topin, Orlando Rivera y Karl Madrid fueron separados por conductas inapropiadas y escandalosas (Mi Diario, 21 de septiembre del 2019). Ambos casos han dejado en evidencia una vez más la doble moral y el encubrimiento que ha tenido la iglesia católica hacia la homosexualidad dentro de sus propios líderes religiosos en Panamá. Desafortunadamente esta no es la primera vez que esto sucede.

Al momento de redactar este ensayo, el gobierno del actual Presidente, Laurentino (Nito) Cortizo, ha encontrado su primer tropiezo con la Asamblea Nacional de Diputados, la cual se ha catalogado como más conservadora que la anterior. Recientemente, el pleno de la Asamblea aprobó modificar el Artículo 56 de la Constitución de la República para que el Estado solamente reconozca el matrimonio entre un hombre y una mujer, cerrando así la posibilidad de una unión civil entre personas del mismo sexo. Esto ha provocado que activistas pro-derechos de las poblaciones LGBTIQ+, estudiantes universitarios y demás agrupaciones hayan realizado una serie de protestas en los predios de la Asamblea. Uno de los miembros fundadores de IPDH, que prefirió mantenerse en el anonimato por temor a represalias, manifestó:

IPDH impulsó los acercamientos con otros sectores para ir contra estas reformas, pues consideramos que atenta contra los Derechos Humanos en particular y en especial contra 
la comunidad LGBTIQ+ en Panamá. Consideramos que los cambios propuestos desde la Asamblea son el resultado de la posición fundamentalista religiosa de algunos diputados que legislan a partir de sus prejuicios personales y sus ideas religiosas. Esto va en contra de una Asamblea Nacional que debería tener la capacidad de garantizar los derechos de toda la ciudadanía sin distingos

Durante una de las últimas manifestaciones, el diputado Jairo (Bolota) Salazar manifestó que en reunión con pastores evangélicos estos agradecieron a la Asamblea Nacional la prohibición del matrimonio igualitario y que por tal razón, "los gais no podían entrar en la Asamblea porque ellos son gais”. Tal declaración homofóbica por parte de Salazar levantó la insatisfacción de los líderes LGBTIQ+ y sus aliados a continuar con una serie de protestas en los predios de la Asamblea, los cuales han sido víctimas de atropellos, arrestos y hasta torturas por parte de la policía nacional.

En total se hicieron 98 aprehensiones. Se estima que un 20\% de miembros de la comunidad LGBTIQ+ fueron arrestados. "Cuando los policías identificaban que eran de la comunidad por sus distintivos o expresión de género los niveles de agresión y violencia se incrementaban. Les decían: "locas", "mariconas", "cuequitos". Los chicos trans fueron manoseados y humillados, principalmente por el personal femenino de la Policía Nacional" (testigo anónimo).

Se nos informó que estas agresiones y atropellos van a ser llevados ante instancias de derechos humanos a nivel internacional. Desafortunadamente, lo que ha acontecido en Panamá en las últimas semanas ha dejado al descubierto ante el mundo lo que sufren las poblaciones LGBTIQ+ por falta de leyes que protejan la vulnerabilidad de estas minorías.

\section{Conclusión}

Desde que vine a vivir en los Estados Unidos, hace ya 20 años, la economía de Panamá ha crecido más que en cualquier otro país de la región, con una gran afluencia de inmigrantes, especialmente de América Central y del Sur, y otras partes del mundo debido a la construcción de las nuevas esclusas en el Canal de Panamá y su creciente economía. Estos cambios también han dado lugar a la creación de organizaciones de base que con el apoyo de organizaciones internacionales, abogan por grupos históricamente oprimidos. Hace más de 20 años, un grupo de panameños liderados por Ricardo Beteta Bond, fundó la Asociación de Hombres y Mujeres Nuevos de Panamá (AHMNP). La misión de AHMNP es mejorar la 
calidad de vida de las poblaciones LGBTIQ+, de hombres que tienen sexo con hombres (HSH), y mujeres que tienen sexo con mujeres (MSM). Estas organizaciones de base ofrecen capacitación sobre temas de salud, y derechos humanos de los individuos y de la diversa población de Panamá. A través de los años, AHMNP y Ricardo Beteta Bond se han convertido en la cara del grupo LGBTIQ_+ en Panamá. Lamentablemente, a causa de la homofobia, la ignorancia, la doble moral y la falta de apoyo gubernamental a esta comunidad marginada, la Asociación AHMNP sigue luchando por un mejor trato al grupo LGBTIQ+ y la creación de una ley estatal contra la discriminación en Panamá. Beteta Bond expresa:

Aunque muchas personas dicen que no existe discriminación hacia las personas LGBTIQ+ y que Panamá tiene mucha tolerancia a este respecto, la verdad es que la discriminación y la homofobia siguen presentes en nuestra vida cotidiana; ambos están arraigados y gozan de gran aceptación. Como resultado, algunas personas ni siquiera se dan cuenta de que han experimentado discriminación y homofobia, sentimientos que se dan incluso en las oficinas gubernamentales (Comunicación personal, 2 de julio de 2016)

A través de los años, la AHMNP ha aprendido a superar múltiples obstáculos sociales y gubernamentales; ha desarrollado una imagen internacional, lo cual constituye la razón por la que decidí incluirla en mi artículo. Algunos de los logros y eventos más relevantes de la AHMNP incluyen la eliminación de la ley que penalizaba la homosexualidad en 2008; el Festival de Cine Gay / Lésbico en julio; el Día Internacional contra la Homofobia en mayo; el Gran Huevo Rosa, un premio anual otorgado a una personalidad local (politicos y personas de los medios de comunicación) que haya manifestado posiciones homofóbicas; el Desfile del Orgullo Gay por más de 12 años; dos estudios diagnósticos sobre el VIH en hombres homosexuales y HSH; y un premio anual a las empresas que apoyan a la organización. AHMNP también se ha convertido en el trampolín para apoyar la creación de otros grupos de base que proporcionan servicios de salud y asesoramiento al grupo LGBTIQ+. Alguno de estos grupos son: Nuevos Horizontes, Asociación Panameña de Personas Trans y Mujeres de Panamá con Dignidad y Derechos, (R. Beteta, comunicación personal, 27 de Mayo, 2016).

A pesar de que ha habido cambios significativos en cuanto a la defensa de la comunidad LGBTIQ+ en Panamá, todavía queda mucho por hacer. Por ejemplo, no existe una ley estatal que proteja a los individuos LGBTIQ+ contra prácticas homófobas por parte de la policía, 
los hospitales, empleadores y otras instituciones gubernamentales. Es importante destacar que aun cuando las autoridades representativas de Panamá asisten y firman compromisos internacionales para proteger a las personas contra cualquier tipo de discriminación, incluida la orientación sexual, en la práctica esos derechos no se ponen en práctica. Quiroja (2000) expone:

Gays y lesbianas no son simplemente seres que participan en una serie de prácticas sexuales. Esta visión es una construcción cultural del capitalismo y, al mismo tiempo, pueden representar modos de desafí que utilizan las herramientas del capitalismo para socavar sus paradigmas represivos (p.12).

Panamá, al igual que la mayoría de los países latinoamericanos, moldea la vida de las personas a través de dos estándares: la orientación sexual abierta no es socialmente aceptada, a menos que se tenga un "buen apellido" o se posea un buen estado financiero. Sin embargo, aquellos hombres (usualmente de bajos estratos sociales) que declaren abiertamente su orientación sexual son comúnmente utilizados por los medios de comunicación como comodines para aumentar sus ganancias durante los carnavales y los concursos de belleza, perpetuando la idea del gay como un hombre que actúa y quiere sentirse como una mujer.

Los medios de comunicación locales por lo general aumentan su índice de audiencia utilizando estereotipos y el acoso contra los panameños homosexuales. Es muy común ver a hombres, unos abiertamente homosexuales y otros definiéndose como heterosexuales, vestidos de mujer en la televisión, con amaneramientos exagerados y hasta grotescos. Por otro lado, autores panameños como Beleño (1991), Britton (1999, 2002) y Pulido Ritter (1998 [2005]) se han referido a la homosexualidad; sin embargo al igual que los medios televisivos, sus interpretaciones de la orientación sexual perpetúan la asunción tradicional de un hombre afeminado o una mujer parecida a un hombre. Por ejemplo, en su obra Miss Panamá, Inc., Britton (1999) define a Ricardo como "homosexual y se le nota" (p. 147). Esto perpetúa la norma de que a los homosexuales les llama la atención los concursos de belleza y que todos son exageradamente amanerados. Por su parte, Pulido Ritter (2005) en su obra Recuerdo Panamá hace referencia a los hombres gays como mariposas,

--Es una mariposa - dijo levantándose de la silla. 
La palabra mariposa me parecía muy bonita. Ernesto, sin saberlo, tenía un amigo que era una mariposa. Entre mis cinco y nueve años, iba a buscarme en la escuela con este amigo que era muy simpático por su risa y por sus chistes. Entre sus chistes le escuche decir que la ciudad estaba llena de mariposas y que cada verano eran muchas más (p. 59).

Durante la obra el narrador cuenta cómo termina asistiendo a la fiesta de las mariposas. Pulido Ritter define a Brigitte como una mariposa de peluca rizada y roja, guantes blancos, vestido negro con la espalda abierta y zapatos de plataforma. Algo que llama mi atención acerca de la fiesta de Brigitte es cuando Pulido Ritter relata que los "globos de diferentes colores colgaban del techo, mucha serpentina había sobre el piso, y muchos hombres bailaban desnudos en la sala" (p. 59). Esta interpretación de una fiesta gay hace más alusión a actos de sodomía y promiscuidad entre hombres. Por otro lado, Marimacha (con mayúscula), es una mujer que tiene aspecto masculino y se esfuerza por llevar a cabo todo como si fuese un hombre. Esto sorprende mucho a todos en el momento en que por primera vez rechaza que la llamen Marimacha:

En el bus de Orejón dijo que me dejara de ahuevazones con Marimacha y ella dijo que no quería que la siguiéramos llamando así. Sorprendidos la miramos.

--¿Qué? ¿No quieres que te llamemos Marimacha?

--No me gusta ese nombre.

--¿Por qué no? One Way te conoce así.

--No entiendo, Marimacha. Entonces, ¿Cómo te vamos a llamar?

--Con mi verdadero nombre.

--¿Alguien sabe cuál es el nombre verdadero de Marimacha?

--jNadie!

--No quiero que me llamen así. Ustedes saben que me llamo Edith (p. 103).

Desafortunadamente, es triste ver cómo los gays y lesbianas compran esta idea de conseguir lo que yo llamo aceptación espacial, haciendo que la gente se ría de ellos mientras usan sus cuerpos (gestos amanerados) y un determinado lenguaje exagerado para mostrar su homosexualidad, internalizando así expectativas socialmente construidas. También es común oír a personas que previenen a los hombres solteros que si se emborrachan durante los 
carnavales en Las Tablas (pequeña ciudad en el interior del país, famosa por ser el punto de encuentro los gays durante el carnaval) terminarán en la cama y teniendo sexo con otro hombre.

La ciudadanía panameña, especialmente la de los medios de comunicación y aquellos en posiciones de liderazgo, necesitan educarse sobre la población LGBTIQ+. Los funcionarios del gobierno deben abogar y aprobar una legislación estatal contra cualquier acto de discriminación hacia este grupo vulnerable, además de luchar para que se proteja y acepte a las personas que no se ajustan a las definiciones hetero normativas y a la eliminación de las prácticas homofóbicas tomadas como normales por la sociedad en general. Mi objetivo es que este informe se una a los de Stanziola, Beteta y muchos otros escritores panameños y extranjeros que abogan por mayor justicia social y respeto hacia los grupos vulnerables. Es de suma urgencia el documentar nuestras experiencias desde un punto de vista históricosocial y analizar las formas en que estas marcan y definen nuestras conductas en diferentes situaciones, espacios, y tiempos. Panamá, por su posición geográfica, ha tenido un auge increíble de inmigrantes de varios países de nuestro continente, al igual que desde Europa. Estas nuevas migraciones también traen consigo diferentes formas de pensamiento e interpretación. Exhorto a investigadores, académicos, líderes y demás personas interesadas, a documentar y analizar las historias colectivas del grupo LGBTIQ+ en Panamá, respetando sus propias definiciones e interpretaciones de sus preferencias sexuales. Es importante recalcar que Panamá como punto de tránsito siempre está en permanente cambio social y económico, lo que lleva a diferentes grupos a reinventarse, adaptarse y reclamar justicia social. Es importante crear espacios donde diversos grupos vulnerables como el LGBTIQ+ puedan narrar y expresar sus testimonios para así, romper con ideas y formas estereotipadas y homofóbicas construidas en nuestra sociedad desde la colonización hasta el presente.

\section{Referencias}

Anzaldúa, Gloria. (2007). Borderlands/La Frontera: The new mestiza (3rd ed.). San Francisco, CA: Aunt Lute Books. 
Bañales, Xamuel. (2014). Joteria: A decolonizing political project. Aztlan: A Journal of Chicano Studies, 39(2), 155-165.

Beleño C., Joaquin. (1991). Gamboa road gang: Los forzados de Gamboa. Panama, Rep. of Panamá: Manfer, S.A.

Beteta Bond, Ricardo. Entrevista personal. 2 de julio de 2016.

Britton, Rosa María. (1999). Teatro. Panama, Panama: Litho Editorial.

Calvo-Quiroz, William. (2014). The aesthetics of healing and love: An epistemic genealogy of jota/o aesthetic traditions. Aztlan: A Journal of Chicano Studies, 39(1), 181-194.

Coloma, Roland Sixto. (2013). Ladlad and parrhesiastic pedagogy: Unfurling LGBT politics and education in the global South. Curriculum Inquiry, 43(4), 483-511.

Cruz, Cindy. (2012). Making curriculum from scratch: Testimonio in an urban classroom. Equity And Excellence in Education, 45(3), 460-471.

Donoghue, Michael E. (2014). Borderland on the isthmus: Race, culture, and the struggle for the canal zone. Durham, NC: Duke University Press.

Driskill, Qwo-Li, Finley, Chris, Gilley, Brian Joseph, \& Morgensen, Scott Lauria. (2011). Queer indigenous studies:Critical interventions in theory, politics, and literature. Tucson, Arizona: The University of Arizona Press.

Escándalo en la iglesia católica: Hombre dice que era solicitado por múltiples miembros del clero panameño. Mi Diario. 21 de septiembre del 2019.

González, Marlin. (2018). "Derechos sexuales en Panamá y su invisibilización en elEstado.” Revista Sexología y Sociedad 24.2: 89-93.

González, Ray. (1996). My macho: Latino men confront their manhood. First Anchor Books.

González, Rigoberto. (2006). Butterfly boy: Memories of a Chicano mariposa. Madison, WI: The University of Wisconsin Press.

Hames-García, M. R. (2014). Joteria studies, or the political is personal. Aztlan: A Journal of Chicano Studies, 39(2), 135-141.

Hames-García, Michael \& Martínez, Ernesto Javier. (2011). Gay Latino studies: A critical reader. Durham, NC: Duke University Press. 
Jacobs, Sue-Ellen, Thomas, Wesley, \& Lang, Sabine. (1997). Two-Spirit people: Native American gender identity, sexuality, and spirituality. Chicago, IL: University of Illinois Press.

Kempe, Frederick. (1990). Divorcing the dictator: America's bungled affair with Noriega. New York, NY: G. P. Putnam's Sons.

Koster, Richard M., \& Sanchez, Guillermo. (1990). In the time of the tyrants: Panama: 1968-1990. New York, NY: W.W. Norton \& Company, Inc.

Mignolo, Walter D. (2005). The idea of Latin America. Malden, MA: Blackwell Publishing.

Mejia Miller, Ricardo. Entrevista personal. Miércoles 19 de diciembre de 2018.

Ocampo, Antony C. (2012). Making masculinity: Negotiations of gender presentation among Latino gay men. Latino Studies, 10(4), 448-472.

Pérez, Daniel Enrique. (2014). Toward a mariposa consciousness: Reimagining queer Chicano and Latino identities. Aztlan: A Journal of Chicano Studies, 39(2), 95-127.

Pulido Ritter, Luis. (2005). Recuerdo Panama. Panama, Panama: Articsa.

Pulido Ritter, Luis. (2018). Escribir desde el sexilio. La Estrella de Panamá, domingo 9 de diciembre de 2018.

Quiroja, José. (2000). Tropics of desire: Interventions from queer Latino America. New York, NY: New York University Press.

Ríos Vega, Juan. (2018). Historias desde el sexilio. Ciudad: Impresora Pacífico.

Ríos Vega, Juan. (2017). La conciencia de la mariposa transnacional para entender la homosexualidad en Panamá. Convivencia 3.3 (2017): 81-108.

Ríos Vega, Juan. (2017). An unhealed wound: Growing up gay in Panama. The Bilingual Review/La Revista Bilingüe, 33(4), 76-79.

Rodríguez, Juana María. (2003). Queer latinidad: Identity practices, discursive spaces. New York, NY: New York University Press.

Salas Fonseca, Pablo Ernesto. (2005). La Madrid. Obra de teatro sin publicar. 
Samaniego, Aleida. (2018). Poco avance contra el VIH/sida en Panamá. La Prensa. (diciembre 01, 2018).

Sigal, Peter. (2003). Infamous desire: Male homosexuality in colonial Latin America. Chicago, IL: The University of Chicago Press.

Stanziola, Javier. (2013). Casco Viejo walks: Performing Panama's 'other' sexual space(s).Intervention: International Journal of Post-Colonial Studies, 17(6), 866878.doi:10.1080/1369801X.2014.998261

Stanziola, Javier. (2013). Hombres enlodados. Editorial Mariano Arosemena: Panamá,.

Stanziola, Javier. (2009). Hablemos de lo que no hemos vivido. INAC: Panamá.

Stavans, Ilán. (1996). The Latin phallus. In R. González (Ed.), Muy Macho: Latino men confront their manhood (pp. 143-164). New York, NY: Anchor Books.

Tijerina Revilla, Anita, \& Santillana, José Manuel. (2014). Joteria identity and consciousness. Aztlan: A Journal of Chicano Studies, 39(2), 167-179.

Trexler, Richard C. (1995). Sex and conquest: Gendered violence, political order and the European conquest of the Americas. New York, NY: Cornell University Press.

Tuhiwai Smith, Linda. (2002). Decolonizing methodologies: Research and indigenous peoples. New York, NY: Palgrave.

Urrieta, Luis. (2003). Las identidades también lloran, identities also cry: Exploring the human side of indigenous Latino/a identities. Educational Studies, 34(2), 147-212. 